Peter Simonič

\title{
Pretekle in sodobne oblike skupnega v dolini Trenti
}

Ključne besede: Alpe, gospodinjstva, gmajne, skupnosti, zadruge, rituali, menedžment, demografija, okolje

DOI: $10.4312 /$ ars.8.1.15-37

\section{Uvod}

Namen tega članka je poiskati pretekle in sodobne oblike prakticiranja skupnega, kolektivnega, neposrednega, dogovornega. Ugotoviti želim, kako se oblikujejo in delujejo tovrstne institucije.

VTrentistaizpostavljena dva vidika, kiju sicervslovenskih antropoloških raziskavah redkeje srečamo. To so na eni strani okolijske danosti, ki so v zavesti prebivalcev alpske doline vsekakor bolj prisotne. Seveda »ekološka zavest « danes z velikimi koraki vstopa v urbano in globalno kulturo, vendar na antropološki metodološki ravni v Sloveniji tega še ni mogoče zaznati. Kulturni in socialni antropologi se ukvarjamo v glavnem $\mathrm{z}$ identitetami, dediščino, kulturo in nacionalizmom ter njihovimi soodvisnostmi in regulacijo na lokalni, državni in globalni ravni. Zanimanje za prostor je v antropologiji sicer znova pridobilo na pomenu, vendar praviloma v kontekstu družbene konstrukcije in opomenjanja, ne kot danost in omejitev. Teoretski premisleki gredo v kulturni antropologiji in geografiji celo načrtno stran od te "redukcije« prostora na njegove biofizične značilnosti (Gupta, Ferguson, 1992; Low, Lawrence-Zúñiga, 2003; Mencej, Podjed, 2010).

Drugi dejavnik, ki ga pri preučevanju trentarske družbe ni mogoče zaobiti, je demografija, ki je deloma odvisna od prvega dejavnika, tj. okolijskih danosti (Steward, 1955; Vayda, Rappaport, 1968), deloma pa je posledica družbenih dejavnikov (Barth, 1956; Netting, 1993; Ingold, 1993; Palsson, 1996; Kozorog, 2006). Demografska interpretacija je v slovenski antropologiji pogosto izpuščena (prim. Vranješ, 2005; prim. Knežević Hočevar, 2008).

Dolina Trente je $\mathrm{v}$ preteklih tristo letih zabeležila velika nihanja $\mathrm{v}$ številu prebivalcev. Danes dolino naseljuje manj kot 10 odstotkov prebivalstva iz 19. stoletja in več kot ob koncu 18. stoletja. Zato demografskih dejavnikov v raziskavo ne moremo 
pripustiti kot samoumevne podstati družbenega "razvoja«, ampak lahko šele na ta način razumemo spremembe $\mathrm{v}$ družbeno-ekonomski strukturi kraja, skupnostna prizadevanja, razvojne programe, identitete in prazničnosti.

Družbenosti ali kolektivnosti bom deloma iskal na področju njihovega uprostorjanja (teritorialnost/lastnina, lokalnost, kulturna krajina; Vranješ, 2006, 2008), bežno pa se bom dotaknil pogajanj za uporabo žive in snovne dediščine med različnimi dejavniki Triglavskega narodnega parka (Ledinek Lozej, 2013). Še najbolj premlevam organizacijske smotre in pragmatike ljudi doline Trente skozi institucije sodelovanja, recipročnosti in solidarnosti, pripadnosti in ceremonije. $V$ tej shemi prvi vidik skupnostnega zadeva prostor, drugi vidik družbeno organizacijo, tretji vidik pa praznike oziroma rituale.

K tej usmeritvi me je pritegnila znova aktualna družbena in družboslovna debata o posamezniku in skupnosti, ki se danes pojavlja tako $\mathrm{v}$ zvezi $\mathrm{z}$ ekonomskim in političnim kakor tudi s kulturnim in ekološkim življenjem sodobnega človeka. Širši okvir teh družbeno-gospodarskih sprememb so pojasnili Jean Baudrillard (1981 [1972], 1999 [1981]), Michael Hardt in Antonio Negri (2001), David Harvey (2005), Joseph Stiglitz (2011) in Thomas Picketty (2014), če naštejem le nekaj odmevnejših avtorjev. Nekateri vplivni znanstveni, politični in ekonomski koncepti so se v zadnjih štiridesetih letih zanimivo prekrili.

Od sedemdesetih let 20. stoletja je Garrett Hardin postal eden najbolj citiranih ameriških okoljskih antropologov, saj je v odmevni objavi v reviji Science (Tragedy of Commons, 1968) konceptu skupnostne lastnine (upravljanja), sicer tako pogostem širom sveta, odvzel trajnostno legitimnost. Po Hardinu je trajna raba omejenih virov $\mathrm{v}$ pogojih povečanega števila prebivalcev mogoča le kot zasebna lastnina ali državna lastnina (Feeny in drugi, 1990). V okviru tedanje hladne vojne je bila taka bipolarnost videti povsem logična. Tudi sicer je imel metodološki individualizem na zahodu daljnosežne posledice tako $\mathrm{v}$ ekonomiji in politiki kakor tudi $\mathrm{v}$ antropologiji (Rapport, Overing, 2000, 249-257) in ne nazadnje tudi v Trenti (Miklavčič Brezigar, 1988).

Elenor Ostrom je pozneje (2009) raziskovanje zastavila bolj nevtralno: skupnostno (mikro) upravljanje je rehabilitirala. Zato v njenem raziskovanju predmet družboslovja ne izgine niti v zamišljeni množici posameznikov (in psihologije) niti v prisilah zamišljenega nacionalnega ali globalnega sistema. Življenje je veliko bolj pestro.

S podobnimi vprašanji sta se ukvarjala Pierre Joseph Proudhon (2008 [1846]) in Peter Kropotkin (1972 [1902]), pri nas pa brata Vošnjak in s cerkvene strani še 
Janez Evangelist Krek z ustanavljanjem zadrug (Šuštar, 1999). V dvajsetih letih 20. stoletja se je s to tematiko ukvarjal Andrej Gosar, ko je o socialni ekonomiji pisal kot o tretji možnosti družbenega organiziranja (1924). Ne nazadnje lahko tudi (delavsko) samoupravljanje postavimo v ta miselni tok (Kardelj, 1979). Tudi sodobni interes za drugačno politično-ekonomsko organiziranje družbe zaradi krize kapitalizma se prekrije $\mathrm{z}$ antropološkim zanimanjem za majhne (etnografsko obvladljive) družbene skupine (»gemeinschaften«; Tönnies, 2001 [1887]). David Graeber je z analizo klasičnih opisov »skupnosti brez države « pokazal, da obstaja povsem naravna epistemološka in biografska vez med francosko in britansko antropologijo na eni strani (M. Mauss, A. R. Radcliffe-Brown) in anarhizmom na drugi (Graeber, 2004, 13-23; prim. Barnard, 2003).

Toliko o predmetu in metodologiji raziskovanja. V nadaljevanju bom predstavil zgolj pripovedne niti in prakse, ki se pletejo med domačini (Simonič, 2011-2014). Uporabil sem tudi transkripcije intervjujev z okoli 60 stalnimi naseljenci doline (Simonič, 2014a, 2014b). ${ }^{1}$

Kaj torej domačini mislijo in kaj delajo skupaj in za skupnost? Na spletni strani Turističnega društva Soča-Trenta naštejejo naslednje lokalne organizacije in društva: Informacijsko središče Triglavskega narodnega parka, Turistično društvo Soča-Trenta, Turistično društvo Soča-Lepena, Kulturno društvo Triglav Trenta, Krajevna skupnost Soča-Trenta, Zadruga Soča-Trenta, Športno društvo Soča-Trenta, Društvo podeželskih žena doline Trenta ter Lovska družina Soča (spletna stran Turističnega društva SočaTrenta, 2014). Vse institucije niso niti enako zagnane niti enako pomembne. K tej »javni« (spletni) strukturi lokalnih kulturno-turističnih organizacijskih vozlišč in skupin moramo vsekakor prišteti še tiste, ki jih sicer ni na seznamu, so pa kljub temu zelo pomembne za materialno in idejno reprodukcijo prebivalstva in skupnosti $\mathrm{v}$ dolini (prim. Douglas, 1986).

1 Članek je rezultat dveh večjih raziskovalnih projektov. Projekt pod vodstvom dr. Jurija Fikfaka z ZRC SAZU je nosil naslov Triglavski narodni park: dediščina, akterji, strategije, vprašanja, rešitve (J6-4310, 2011-2014). Druga spodbuda za preučevanje trentarske družbe je prišla s strani projekta dr. Božidarja Jezernika Prazniki in oblikovanje nacionalne skupnosti na Slovenskem (J6-4007, 2011-2014). Pogovori, zapiski, drugi dokumenti ter zvočni in video zapisi iz Trente so shranjeni v dokumentaciji Oddelka za etnologijo in kulturno antropologijo Filozofske fakultete Univerze v Ljubljani, Zavetiška 5 (Gradivo Triglavski narodni park, 2011-2014).

Etnografsko gradivo je nastajalo med več obiski v Trenti in Bovcu. Analiziral sem dostopno družboslovno in humanistično literaturo, pregledal domoznansko zbirko v knjižnici pri Kulturnem domu Bovec, prisostvoval nekaterim javnim dogodkom in debatam ter dolino doživel v različnih sezonah.

Pripravil sem tudi dve študentski raziskovalni delavnici, ki sta bili del učnega načrta: Biografije (april 2012) ter Skupnosti in prazniki (december 2012). Z množico ciljnih študentskih intervjujev o življenjskem spominu domačinov sem dosegel veliko statistično reprezentativnost in tako sem lahko potrdil ali zavrgel nekatere predpostavke iz lastnih opazovanj in pogovorov, odpirale pa so se tudi nove teme. Pedagoško delo je obogatilo poglede v procesu raziskovanja. 


\section{Okolje - gospodarstvo - demografija}

Dolina Trente je od 16. stoletja prešla več ekonomskih in ekoloških obdobij, paradigem in strategij: lovsko-nabiralniško-gozdarsko (neolitik ter romanska, germanska in slovanska kolonizacija), transhumantno-vrtičkarsko-gozdarskoželezarsko-lovsko (16.-18. stoletje; Habsburžani), transhumantno-kmetijskovrtičkarsko-lovsko (19.-20. stoletje; Avstrija) in turistično-okolijsko-vrtičkarskopašno (od 2. polovice 20. stoletja; Slovenija) (Simonič, 2013). Na primeru Trente se lepo kaže novoveško naraščanje upravne in gospodarske moči urbanih središč, ki so imela ugodnejšo geografsko lego in so počasi oblikovala lastna populacijska, delovnoprostočasna obrobja (prim. Southall, 1998).

Po statističnih podatkih občine Bovec je bila rodnost vedno najvišja v Trenti in Soči: približno 6 članov na gospodinjstvo (Abram, 1907; Statistični urad Republike Slovenije, 2002). ${ }^{2}$ Ta prirastek se je uravnaval $z$ odseljevanjem in veliko umrljivostjo zaradi bolezni in nevarnosti (padci, zveri, mraz, gozdarstvo, lakota).

Naravni pogoji ne omogočajo, da bi se prebivalstvo lahko prehranilo. Zato vsako leto konča globlje $\mathrm{v}$ dolgovih. Trentarji niso lastniki svojega premoženja, ampak verniki z Bovca. Kdo ve, kako dolgo bo kmet zdržal in kaj se bo zgodilo? Da bi jim vsaj malo pomagali pri revščini, bi bilo treba vsaj regulirati Sočo in speljati vozno pot vse do Zadnje Trente, da bi lažje prenašali blago in trgovali (Rutar, 1889, 1580).

Možje so konec 19. stoletja pogosto odhajali v tujino: za drvarje v avstro-ogrsko Bosno, Slavonijo in na Koroško ter v nemško Vestfalijo ali za rudarje v ponovno odprt rudnik v Rablju na italijanski strani; celo v ameriško Montano so se podali. Dekleta so čez zimo hodila služit v Trst (Abram, 1907; Komac, 2003, 132).

Prepoved kozjereje (Zakon o gozdovih, 1953), ker da »koze smrdijo« in »delajo škodo v gozdu«, je v spominu domačinov zapisana kot travmatični prelom, kot eksistencialni stres in kriza. Po pripovedovanju naj bi Trenta šla od takrat samo še \#V brezno« - "pod kritično maso«. A ni bila kriva samo prepoved koz. Zaradi sočasne industrializacije se je v mestih po drugi svetovni vojni povečevalo povpraševanje po delovni sili, zato so se odpirale priložnosti za prebivalce Lepene, Soče in Trente. Ljudje so se od petdesetih in šestdesetih let 20. stoletja zaposlovali v industrijskih obratih (tovarne Lesna, Čip, Iskra v Bovcu) in v drugih službah po celotni Primorski in

2 V vasi Trenta je bilo pred dobrim desetletjem 44 gospodinjstev s pretežno osamelimi upokojenci; v Soči je bilo takrat prijavljenih 71, v Lepeni pa 19 gospodinjstev (Statistični urad RS, 2002). Sredi 18. stoletja, po propadu železarstva, je bilo v vasi Trenta vsega 15 naseljenih hiš (Komac, 2003, 41; po Morone, 1755). Sredi 19. stoletja pa je bilo samo v vasi Trenta že 57 hiš s 357 prebivalci (povprečno več kot 6 članov na gospodinjstvo) (Abram, 1907; Komac, 2003, 132). Število prebivalcev v dolini je do začetka prve svetovne vojne še naraščalo, potem pa se je ustavilo in še pada. 
drugod. Nekateri »kmetijski interesenti« iz doline Trente so po drugi svetovni vojni dobili posest v Kočevju.

$\mathrm{Na}$ dnevne delovne migracije je močno vplival tudi razvoj destinacije Alpski turistični center Bovec (in Kanin), kamor so se v sedemdesetih in osemdesetih letih 20. stoletja po navodilih oblasti morali prezaposliti turistični delavci iz Trente. Takrat je prenehal obratovati hotel v Trenti. Kdor je hodil v kakršnokoli službo izven doline, je sčasoma povsem opustil kmetovanje in pašo: „Nimamo niti hišnih ljubljenčkov, saj nas cele dneve ni doma, " smo slišali od sogovornice, ki se dnevno vozi v službo v Bovec. Pri dnevnih migrantih je od kmetijstva ostalo v glavnem le vrtičkarstvo na ohišnici. Njihova gospodinjstva imajo največkrat tri člane.

V obdobju 1970-1989 je zaradi vsega naštetega zavladala »apatija«. Izpraznjena in poceni zemljišča so začeli prevzemati vikendarji iz različnih delov države (Vranješ, 2006) - danes jih je tam več kot domačinov (okrog 330 proti 230). TNP je ob urejanju vsakdanjih življenjskih vprašanj prebivalcev doline Trente pogosto predmet manjših ali večjih sporov, vendar med domačini prevladuje prepričanje, da je njegov naravovarstveni (in turistični) okvir v resnici edina možnost za večino prebivalcev te alpske doline.

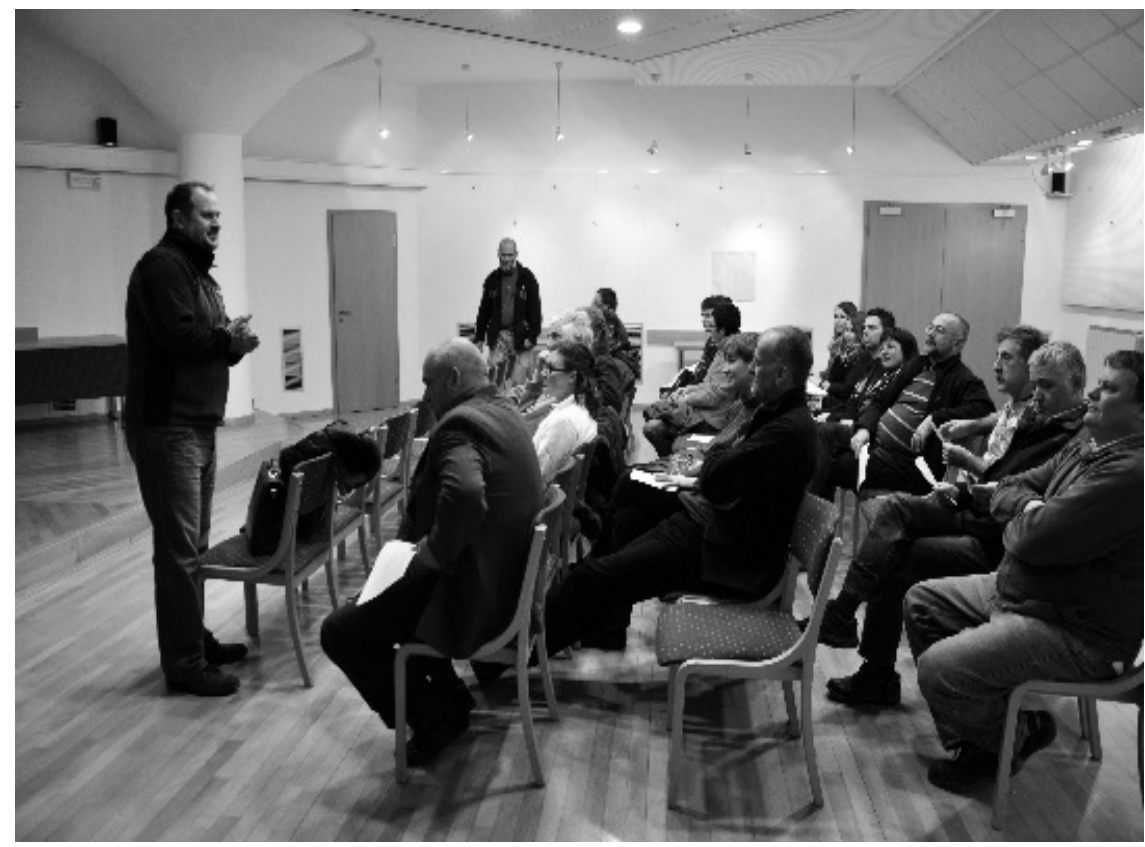

Slika 1: Martin Šolar, direktor Javnega zavoda TNP, v pogovoru z domačini glede priprave novega upravljavskega načrta nacionalnega parka, Kulturni dom Bovec, 30. november 2012. Foto: P. Simonič. 


\section{Gospodinjstva}

Gospodinjstvo velja za temeljno družbeno in ekonomsko enoto ter predstavlja okolje generalizirane - vsesplošne recipročnosti (Sahlins, 1972, 185-200). Po Sahlinsovem mnenju se te vezi $\mathrm{z}$ oddaljevanjem človeka od lastne družine vedno bolj rahljajo in slednjič pripeljejo do t. i. negativne (tržne) recipročnosti (prim. Graeber, 2011, 285). Družinski in sorodstveni odnosi imajo torej pomembno vlogo pri oblikovanju vzajemne pomoči in širšem družbenem sodelovanju ter pomembno prispevajo $\mathrm{k}$ občutenju posameznikove pripadnosti (sprejetost, enakopravnost, moralna zavezanost, velikodušnost).

Po petdesetih letih 20. stoletja so ljudje iz doline Trente oblikovali naslednje strategije preživljanja (virov, rabe prostora) gospodinjstev in njihovih članov:

- Kmetijstvo, vrtičkarstvo, pašništvo (turizem) - velike družine.

- Zaposlitev v industrijskih in upravnih središčih izven doline; dnevni migranti.

- Peščica lokalnih (sezonskih) zaposlitev v administraciji TNP, zadružni trgovini, pri obrtniku (s. p. žaga, gostilne, kampi) ali pri Zavodu za gozdove.

- Uživanje pokojnine (vrtičkarstvo), štipendije.

- Stalna preselitev v oddaljena mesta: zaraščanje kmetijske krajine.

- Prodaja zemljišč vikendarjem (sprememba lastništva): nastanek nove, statistično dominantne in v lokalnem pogledu $\mathrm{v}$ glavnem kulturno in participativno mrtve skupine; nekje vmes so tisti domačini, ki zdaj svojo rojstno hišo v Trenti uporabljajo kot počitniško hišo.

Raziskava, katere rezultate predstavljam v tem prispevku, se je ukvarjala izključno s stalnimi naseljenci $\mathrm{v}$ dolini, zato predstavljam samo prve tri oziroma štiri strategije preživljanja lokalnega prebivalstva: kmečko-pašno gospodarstvo, zaposlitev $\mathrm{v}$ upravnem in industrijskem središču izven doline (sezonske in dnevne migracije) ter zaposlitev pri peščici lokalnih ponudnikov delovnih mest; morda lastna in dodatna turistična dejavnost (kamp, gostilna, apartma). Kombinacije med njimi so prav tako mogoče, nikakor pa ne gresta skupaj na primer kmetovanje in zaposlitev izven doline.

Kdor se v Trenti preživlja samo z lokalnimi viri (kmetijstvom in turizmom), mora sočasno izkoriščati/črpati zelo različne možnosti (travnik, gozd, živali, predelava hrane, gore, voda, tujci). Tak obseg obratovanja obvladuje le velika družina, ki deluje kot družinsko podjetje, čeprav pravno nima takega statusa. Za preživetje iz lokalnih virov je treba veliko delati, veliko več, kot si predstavljamo mestni fantje: vsi delajo (vse), kakor hitro odrastejo. Dva najpomembnejša predstavnika takega gospodarskega modela sta družini Ivana Jelinčiča s Soče in Marka Pretnerja iz Trente (Pri Plajerju). Prva šteje 11 članov, druga pa 6-7, kar ju danes uvršča med 
najštevilčnejša gospodinjstva. Jelinčič ima okrog 2-3 hektarje lastne zemlje in še okrog 25 hektarjev v najemu, Pretner pa ima svojih 5 hektarjev in 15 hektarjev v najemu (travnikov, njiv). Prvi ima 100 ovac, drugi 60. Prvi izdeluje sir, drugi klobase; izdelke prodajata gostom $\mathrm{v}$ času turistične sezone, deloma pa tudi v novoustanovljeni zadružni trgovini v Trenti. Prvi odpre posest za turiste v poletnih mesecih, drugi ponuja nastanitev skozi vse leto. In oba sta pomembna mnenjska voditelja v svojem kraju (habitatu in habitusu; Simonič, 2011).

Sposobnost reprodukcije družin v dolini Trente je danes slaba; ne zadošča za ohranitev, kaj šele za populacijsko rast. Nizka rodnost (zaradi umanjkanja aktivnega prebivalstva) in šolanje otrok (tistih staršev, ki so ostali) sta dodatno pospešila depopulacijo doline. Zgodba o šolstvu $\mathrm{v}$ dolini je značilna za slovenska ruralna območja. Od leta 2011 ima šola v Soči, edina preostala v dolini, samo še en, prvi razred.

Vedno več mladih se je po osnovni šoli odločalo za srednjo šolo v Tolminu, Novi Gorici, pa tudi v Trstu, Kranju, Škofji Loki, Ljubljani, Mariboru in drugod. Generacije po letu 1970 so se vedno pogosteje odločale še za študij. Večina trentarskih fantov in deklet je torej čez teden bivala zdoma, zato so se zgodaj čustveno in eksistenčno ločevali od doma in družine. Malokdo se je po šolanju vrnil, zaposlitev v dolini tako ali tako ni bilo. Zato so si družine ustvarjali povsod drugod.

Možnost ustvarjanja družin in gospodinjstev dodatno otežuje dejstvo, da je prihod vikendarjev krepko povečal vrednost zemljišč v dolini in planini. Zato se mladi v Trenti danes veliko težje osamosvojijo, saj nimajo dovolj kapitala, da bi pridobili posest in vzdrževali družino.

Razvoj tehnologije (kmetijska mehanizacija, transportna sredstva, telekomunikacije, ideologija napredka, racionalizacija delovnih procesov) je povečal avtonomnost in samozadostnost gospodinjstev in jih med seboj polagoma odtujil. Enako velja za televizijo in svetovni splet. Včasih so bili ljudje prisiljeni sodelovati drug z drugim, v agro-kulturni skupnosti niso bili sposobni preživeti sami, so menili sogovorniki. Vedno ko je bil čas za veliko opravilo - na primer mlatenje pšenice, ličkanje koruze, sekanje in rezanje drv, striženje ovac (žensko delo) -, so šli vsak dan/večer k drugi hiši: »Bolj so si pomagali po soteskah, saj so ljudje razkropljeni po dolini, « je povedal sogovornik. »Danes imaš sam motorno žago. Lahko razžagaš en kamijon drv in ne rabiš soseda, da bi ti pomagal. Sedaj je vsak bolj sam.«

Danes je infrastruktura v Trenti v mnogočem podobna tisti iz velikih mest: ljudje uporabljajo mobilne telefone in splet, imajo svoj vodovod, glavne ceste so asfaltirane, avtomobil pri hiši je samoumeven. 


\section{Agrarne skupnosti}

Agrarne skupnosti so zadnjih dvesto let pomembna pravna osnova lokalne ekonomije, v različnih oblikah pa so obstajale že prej, v srednjem veku. Koze in ovce so se v Trenti prosto pasle, saj bi zahtevalo veliko naporov, da bi drobnico pripravili do tega, da bi upoštevala meje individualnih posesti. Zato so se domačini temu izogibali. Prav pašništvo (v gozdovih) naj bi bilo razlog, da ljudje v dolini Trente niso pristajali na deljenje, privatizacijo skupne posesti, in to ne v času Avstrije ne v fašistični Italiji ne v socialistični Jugoslaviji in ne v Republiki Sloveniji, ko so Julijske Alpe dokončno nacionalizirali (v materialnem in kulturnem smislu). Z Zakonom o ponovni vzpostavitvi lokalnih skupnosti ter vrnitvi njihovega premoženja in pravic (Uradni list RS, 1994) so zemljišča s pripadajočimi pašnimi pravicami, ki so bila leta 1947 nacionalizirana, vrnili v last in upravljanje vknjiženim pašnim upravičencem (Ledinek Lozej, 2013, 61). V dolini Trente tem skupnostim znova pripadajo gozdovi in (višinski) pašniki, s katerimi so se dolgo preživljale.

Po 15-20 gospodinjstev na agrarno skupnost je imelo pravico do rabe višinskih ter drugih skupnih pašnikov in gozdov. Pravica do deleža se je prenašala iz roda v rod kot hišna pravica. Deleži, imena in hišne številke nosilcev pravic so bili v zemljiško knjigo vpisani po zemljiški odvezi leta 1848. Le če patriarhalna agrarna skupnost ni povsem zasedla planine, se je lahko s čredo pridružil še kdo drug, tudi iz drugega kraja. 15-20 transhumantnih družin s po 20-30 ovcami si je lahko na planini zagotovilo preživetje in dodaten zaslužek; ostali so se morali znajti znotraj te pravne sheme, se zaposliti v kmetijstvu ali gozdnem gospodarstvu, služiti ali se odseliti.

Kolektivna oblika upravljanja planin je lahko vpisana kot občinska, družbena ali državna last, vendar pa je $\mathrm{v}$ dolini Trente vedno tudi moška in hišna pravica domačinov. Ko je pri hiši več sinov, gredo pravice le tistemu izmed njih, ki je ostal na izvirnem naslovu. Zato lahko rečemo, da so agrarne skupnosti v Trenti patrilokalne pastirske bratovščine, saj je pravica do uporabe skupnih pašnikov vezana na moške potomce in dolgotrajno bivanje njihove rodbine.

"Nekoč«, verjetno do druge svetovne vojne, naj bi bilo na območju Trente kar enajst takih agrarnih skupnosti. V dolini Trente jih zdaj deluje šest. V Lepeni in Soči deluje agrarna/pašna skupnost Duplje in Plazi, v vasi Trenta pa obstajajo kar štiri agrarne skupnosti/planine: Trebiščina, Zajavor, Zapotok in AS vasi Trenta (skupna lastnina). Sicer so v zadnjih štiridesetih letih gmajne izgubljale družbeno-ekonomsko bazo, še vedno pa imajo kolektivno-simbolno (sodelujočo, redistributivno, solidarnostno) funkcijo. Transhumantna dejavnost agrarnih skupnosti je danes tako rekoč zamrla, planšarji so se postarali ali odselili, le po eno gospodarstvo v Soči in Trenti še ima moči 
(delovne sile) za večje število ovac. Še do srede 20. stoletja so imeli v obdobju od maja do septembra v eni planini na skupni paši po 200-400 glav drobnice, to pomeni, da je bilo v vsej dolini Trente skupaj od 2000 do 3000 ovac (11 agrarnih skupnosti x 15 družin x 20-30 ovac); danes jih je v dolini okrog dvesto: »Najprej so šle koze, potem še ovce, « je povedala informatorka.

Nekatere od omenjenih agrarnih skupnosti dajejo danes dele planine v najem (Duplje, Mangart), del dobička pa prenašajo na lokalno oziroma krajevno skupnost. To je specifična pravna dediščina kozjereje, katere materialno plat si lahko danes ogledamo v Trentarskem muzeju pri Informacijskem središču TNP, kot živa dediščina pa je potisnjena v ozadje in močno preobražena. Agrarne skupnosti v dolini LepeneSoče-Trente so $\mathrm{v}$ turistični reprezentaciji pod povprečjem nekaterih drugih živih planšarskih dediščin, ki jih je na območju Triglavskega narodnega parka nedavno zabeležila Špela L. Lozej (2013).

Zanimivo je razmerje med drobno individualno/malo posestjo $\mathrm{v}$ dolini ter skupnim zemljiščem na višinskih, sezonsko dostopnih obrobjih doline. $\mathrm{Ne} \mathrm{le,} \mathrm{da}$ so si planinsko pašno območje čim bolj enakomerno razdelili med člani skupnosti (gospodinjstvi), ampak so upoštevali tudi morebitno razliko $\mathrm{v}$ njihovi uspešnosti: po enem tednu so namreč izmerili, koliko ima vsak mleka, najuspešnejši pa je moral presežek odslužiti z delom pri sirjenju, vzdrževanju skupnih prostorov in kolovozov in podobno. Toda ob propadanju transhumance in umikanju na nižinsko pašo Trentarji niso ohranili skupnostnih ekonomskih praks in institucij, povezanih $\mathrm{z}$ ovcami: $\mathrm{v}$ planinah so ljudje molzli in delali sir skupaj, $\mathrm{v}$ dolini pa pozneje niso ustanovili niti enega skupnega obrata. Zdaj se s sirarstvom resneje ukvarjata samo kmeta Jelinčič iz Soče in Mirko Vertelj s Skale.

Članom agrarnih skupnosti v Trenti zdaj pripada v glavnem gozd. Z gozdarstvom so se domačini do sredine 20. stoletja zelo intenzivno ukvarjali za lastne energetske in gradbene potrebe; zemljišča so krčili za njive in vrtove, pašnike in ceste. Avstrija je hlodovino že od 16. oziroma 17. stoletja izvažala v Benečijo. V 19. stoletju naj bi bila večina moških gozdarjev. Več ur so lahko stali v mrzli Soči in poravnavali hlode, ki naj bi jih odplavilo po reki, pri tem pa venomer kadili pipice in cukali žganje (Abram, 1907). Še v šestdesetih letih 20. stoletja je v dolini delalo okrog petinosemdeset gozdarjev, danes pa mehanizirana gozdarska dejavnost domačinom daje samo še dve delovni mesti. ${ }^{3}$ Od prodaje biomase (v Trenti skupaj od 1000 do 3000 kubikov lesa letno) naslednikom pravic iz agrarne skupnosti danes pripada del dohodka. Pred

3 Upravljanje z gozdovi pripada javnemu Zavodu za gozdove (od 1954 do 1991 imenovanemu Gozdno gospodarstvo) in njegovim podizvajalskim podjetjem. Zavod ima zakupljeno večino občinskih (bovških) gozdov. Takoj za njim imajo pravico do participacije predstavniki občine in člani lokalnih oziroma agrarnih skupnosti. 
nedavnim so v Informacijskem središču v Trenti opustili gretje s plinom in inštalirali peč na sekance (iz lokalnih gozdov); na ta način se povezujejo agrarna skupnost, lokalna obrt (žaga v Soči) in IS TNP v Trenti.

Agrarne skupnosti naj bi bile notranje solidarne. Po pripovedovanju informatorja ima vsak v vasi Trenta pravico do lesa iz skupnih/agrarnih gozdov, tudi če uradno ni član bratovščine. »Eno je članstvo, drugo pa kaj lahko dobiš. «4

\section{Zadruga}

Po vojni, v petdesetih letih, naj bi v Soči delovala (državna) zadruga, ki je odkupovala lokalne kmetijske pridelke (sir, jagenjčke).

V devetdesetih letih 20. stoletja so ustanovili razvojno Zadrugo Soča-Trenta, da bi zgradili malo hidroelektrarno Krajcarca. Prispevek za članstvo je bil takrat 500 nemških mark (okrog 250 evrov) in štirideset ur obveznega prostovoljnega dela. Iz centrale zdaj letno v omrežje pošljejo za 400.000 evrov električne energije. Razvojna zadruga je med drugim še koncesionarka za pobiranje parkirnine na prelazu Vršič ter upraviteljica okrepčevalnice Kamba na Logu v Trenti. Ukvarjajo se tudi s preskrbo lokalnega prebivalstva. $\mathrm{V}$ dolini je do nedavnega obratovala samo ena trgovina $\mathrm{z}$ osnovno špecerijo. Prva večja trgovina je bila takrat v Bovcu (ali čez Vršič v Kranjski Gori, Kranju ipd.), zato so za osnovno oskrbo porabili veliko časa in denarja.

Leta 2013 so v vasi Trenta odprli novo trgovino, ki jo financirajo iz drugih dohodkov razvojne zadruge. Hitro dostopna in dobro založena trgovina v teh krajih ni mala stvar, sploh pozimi. ${ }^{5} \mathrm{Z}$ njo ustvarijo od 30.000 do 60.000 evrov letnega prometa, $\mathrm{z}$ dvema potujočima trgovinama pa nameravajo v kratkem ustvariti do 400.000 evrov letnega prometa; v »tržničnem delu« zadružne trgovine lahko nekateri domačini prodajajo svoje pridelke in izdelke. V trgovini so omogočili zaposlitev trem Trentarjem. Razvojna zadruga ima v svojem programu tudi skrb za urejanje stanovanjskega problema mladih ter pomoč pri izgradnji turistične in druge infrastrukture.

\section{Turistično omrežje in društvene dejavnosti}

Tretja strategija preživetja na zgornjem seznamu je vključevala turizem. Trentarji zdaj dolino prodajajo kot destinacijo, ne kot objekt kmetijskega obdelovanja, paše ali izkopavanja železove rude. Ekosistema ne izkoriščajo le prek njegovih surovin, kar

4 O različnih in drugačnih vplivih agrarnih skupnosti na lokalno družbeno organizacijo in ekonomski razvoj glej Kozorog (2009, 177-180).

5 Poleti, ko pridejo turisti, je zanimanje še posebej veliko, zato se ponekod v kampih odprejo sezonske trgovinice. 
je bilo značilno za ves novi vek, ampak kot distinktivno kulturno krajino, ambient in doživetje.

Trenta je pred 150 leti postala objekt znanstvenega čudenja, poezije in (slovenskega) domoljubja. Zapisi o Bovškem in Trenti so se v drugi polovici 19. stoletja pomnožili: o njiju so pisali Štefan Kociančič (objave v Zagrebu,1854), baron Karl Czernigvon Czernhausen (Das Land Görzund Gradisca: mit Einschluss von Aquileja, 1873), Morelli di Schönfeld (Istoria della Contea di Gorizia, 1855-1856), Anton Červ (objava v goriškem Glasu, 1874), Simon Rutar (Zgodovina Tolminskega, 1882), Vatroslav Holz in Simon Gregorčič ml. (etnološki zapisi v časopisih Slovan in Soča, 1884), Josip Abram (1907), Viktor Dvorský (Studie ku Geografii Slovanských Sídel: Trenta, 1914) (Marušič, 2002; Komac, 2003; Kozorog, 2009). Sledila je »zlata doba odkrivanja Julijskih Alp«, z očetom slovenskega alpinizma dr. Juliusom Kugyjem (Wraber, 1980; Komac, 2003; Šaver, 2005). Triglavski narodni park je torej ob koncu 20. stoletja v dolini institucionaliziral že obstoječi spoj naravoslovja, meščanske politične mitologije in turizma (planinstva).

Zasebna in planinska gostinska ter namestitvena (ekološko-turistična) ponudba je v dolini obstajala celotno 20. stoletje, najprej v vasi Trenta. Veliko zasebnih namestitev je bilo na voljo tudi v času Socialistične Republike Slovenije. Od osemdesetih let 20. stoletja se je ta dejavnost zelo povečala, statistično toliko bolj opazno, če upoštevamo hkratno upadanje števila prebivalcev. Zaradi uspešnosti turistične panoge so se med ljudmi povečale težnje po tržnem gospodarstvu (Miklavčič Brezigar, 1988). ${ }^{6} \mathrm{Na}$ drugi strani je prav turistična izkušnja marsikaterega obiskovalca prepričala, da si je $\mathrm{v}$ dolini zaželel poceni počitniško hišico (med njimi številni nosilci najpomembnejših znanstvenih, gospodarskih in političnih funkcij v državi) (prim. Celec, 2014); po pripovedovanju so gostje, ki prihajajo, »res izobraženi ljudje«. Povratno ima Trenta pomembno čustveno in simbolno vrednost v nekaterih ključnih državnih ustanovah, obenem pa višjo ocenjeno vrednost nepremičnin. Turizem po eni strani prinaša svetovljanstvo, saj se domačini v poletnih mesecih srečujejo še z Nemci, Avstrijci, Belgijci, Nizozemci in drugimi tujci, po drugi strani pa turizem povečuje odvisnost doline od življenjskih pogojev in pričakovanj v širšem evropskem prostoru (kupna moč, politično dogajanje, cestne povezave, kulturna industrija in stil ipd.).

Dolina dolžine 30 kilometrov danes premore šest kampov, tri turistične kmetije, štiri gostišča, dve okrepčevalnici, dve kongresni dvorani, dvanajst ponudnikov apartmajev, trinajst ponudnikov sob in sedem planinskih koč: skupaj je v dolini na voljo petsto šotorišč in več kot štiristo ležišč (Turistično društvo Soča-Trenta, 2014). ${ }^{7}$

6 Ne pozabimo, da so nekateri z denacionalizacijo dobili povrnjene tudi pravice iz agrarne skupnosti.

7 V primeru polne zasedenosti bi lahko bilo obiskovalcev štirikrat toliko, kot je domačinov. 
Opazimo lahko, da se večina prireditev zvrsti v poletnih mesecih, ko lahko domačini s skupnim delom zadovoljijo tudi pričakovanja turistov. »Takrat je tukaj klima čudovita ... tu se lahko v poletnih mesecih zadiha svež zrak, ljudje se kopajo v Soči.« »Že sami turisti prinesejo s seboj tisti vrvež, dogajanje je vsak dan pozno v noč ... Ponavadi imajo tudi kar glasno glasbo, predvsem vikendi so še bolj pestri in če pride mladina. Družine so razumljivo bolj pridne.« Pozimi pa je alpska dolina videti povsem drugače: domačini se držijo doma, turisti nimajo kaj početi, saj so takrat gozdovi in planine neprehodni in megleni, Soča pa ledeno mrzla.

V dolini delujeta dve turistični društvi: Soča-Trenta in Soča-Lepena. Drugo so ustanovili leta 2005, saj so bili nekateri Sočani in Lepenčani - med njimi tudi vikendarji in upokojeni povratniki - prepričani, da Soča stagnira ter da je preveč dogajanja in denarja zbranega v vasi Trenta. Trend relativnega nazadovanja Soče in napredovanja vasi Trenta v preteklih petdesetih letih je dejstvo, vendar ne zaradi trentarske zarote, ampak zaradi bolj agilne mlade generacije. Rivalstvo med vasema ima sicer dolgo brado: še vedno je namreč živ spomin na »obvezen pretep«, do katerega je prišlo, ko so se v kateri od vaških gostiln srečali fantje iz Lepene, Korit, Soče in Trente. »To je del folklore, ki ga je težko razumeti, « je povedal starejši priseljenec, ki je bil s tovrstno identifikacijo soočen po drugi svetovni vojni. K temu občutenju s strani Sočanov danes gotovo prispeva postavitev Informacijskega središča TNP v vasi Trenta ter domnevna družbena omrežja in privilegiji, ki so se povsem spontano napletli okrog te ustanove. Po drugi strani je bila nekoč pošta v Soči. V tamkajšnji cerkvi sv. Jožefa so še vedno redne maše za vso dolino. Tam delujejo šola in številni kampi itd. V očeh Sočanov ni razloga, da bi se blagovna znamka doline vrtela samo okoli imena Trenta, kar zunanji opazovalci počnejo (spet) spontano, saj celotna dolina nosi ime po vasi na njenem skrajnem koncu. Trentarji seveda nimajo nič proti tej logiki pars pro toto. Pripadnost vaškim skupnostim ni toliko izključujoča, da se ljudje ne bi dobili pri skupni maši, da bi ne izvedli skupnega projekta ali da bi se v dolini ne poročali fantje in dekleta iz sosednjih vasi.

V sklop oživljanja Trente v osemdesetih letih 20. stoletja, ko naj bi popravili uničujočo državno politiko, je spadal tudi mladinski klub, ki je takrat deloval v stavbi na mestu današnjega Informacijskega središča. To se mi zdi pomembno zato, ker prav iz vrst mladinskega kluba $\mathrm{v}$ Trenti prihajajo današnji organizatorji Trentarskega senjema in lastniki gostišč - nosilci ekonomskega in javnega življenja v kraju -, mladi in aktivni člani nekaj družin, ki ostajajo $\mathrm{v}$ dolini in so aktivni na številnih področjih, $\mathrm{v}$ društvih, skupinah in zadrugi. Sloj prebivalcev, ki je $\mathrm{v}$ takih razmerah sposoben institucije ohranjati pri življenju, je izjemno tanek, okrog 30 ljudi. Ta skupina ljudi je obdana $\mathrm{z}$ upokojenci, saj je povprečna starost $\mathrm{v}$ Trenti okrog šestdeset oziroma sedemdeset let. Starejše ženske so doma, na vrtovih, v soseččini, srečujejo pa se 
tudi pri mašah, pogrebih in občasno v trgovini. Kontinuiteta od mladinskega kluba do aktivnega prevzemanja upravljanja skupnosti se je pozneje izgubila, ker se je nadaljevala depopulacija (»pod kritično maso«), deloma pa tudi zaradi odprtja novega Informacijskega središča TNP (1995).

S časom sta se oblikovali dve umetniški skupini, ki delujeta v okviru Kulturnega društva Triglav Trenta: zelo star moški pevski zbor ter mlajša in manj aktivna dramska skupina. Tradicionalno sta bila pomembna še gasilsko in lovsko društvo. Oblikovanje skupin lahko opazujemo še pri mašah in praznikih zavetnikov (Soča - sv. Jožef, 19. marec; Trenta - sv. Ana, 26. julij). Srečujejo se tudi na sestankih. Nekateri starejši moški se dobivajo na kegljaških večerih ob stari konjušnici v Trenti.

Domačini se enkrat letno v velikem številu zberejo na Trentarskem senjemu, največji letni zabavi $\mathrm{v}$ teh krajih. Med javnimi dogodki omenimo še vsakoletni poletni počitniški tek od Soče do Lepene (prvo soboto v avgustu). Pomemben postaja Trentarski forum, desetdnevna mednarodna glasbena šola za okrog dvajset izbranih mladih talentov $\mathrm{z}$ vsega sveta, ki jo v juliju in avgustu že več kot desetletje organizira Dunajska filharmonija (v stavbi IS TNP v Trenti).

Pri organiziranju teh dogodkov sodeluje že omenjena skupina okrog dvajsetih do tridesetih aktivnih prebivalcev, pomagajo pa jim njihovi otroci in stari starši, eni prek kulturnega društva, drugi prek turističnega društva, tretji prek aktiva kmečkih žena ali lovskega društva.

\section{Trentarski senjem in Sv. Ana}

Trentarski senjem (sejem) je odličen indikator strukturnih sprememb v celotni dolini Trente. Tako na ravni eksistence ter njenega zaodrja (Turner, 1967) kakor tudi simbolov (Cohen, 1998 [1984]) in prazničnih prostorsko-časovnih postavitev (Gluckman, 1940) se kaže premik od agro-kulturnega (v našem primeru transhumantnega) $\mathrm{k}$ turističnemu modelu družbene in gospodarske organizacije (prim. Poljak Istenić, 2013). Zaznati je mogoče občuten vpliv državnih politik na te procese.

Izvorno je bil Trentarski senjem ob malem šmarnu - 8. septembra, na rojstni dan Device Marije. Takrat so priredili veliki sejem večinoma plemenske živine za bovško in gorenjsko regijo. Sejem se je obdržal do prve svetovne vojne, po njej pa so nove italijanske oblasti prepovedale zborovanja in drugače ovirale javno življenje Slovencev. Po drugi svetovni vojni, v času socialistične oblasti, javna zborovanja niso bila vedno sporna, gotovo pa so bili nezaželeni cerkveni prazniki. Obe oblastni intervenciji sta pomagali pokopati tradicijo »izvornega« živinskega sejma. Danes, sto let pozneje, 
je Trentarski senjem znova živ, a drugačen. Njegovo ponovno rojstvo popolnoma sovpada $z$ ustanovitvijo IS TNP (1996).

Zdaj je senjem serija okrog desetih kulturno-turističnih dogodkov: razstave, koncerta, dokumentarnega filma, vodenja v planino, otroške ustvarjalne delavnice ipd. Sklop doseže vrh mesec in pol pred nekdanjim senjemom - na god sv. Ane, matere Device Marije in zavetnice vasi Trenta (26. julija). Takrat pred stavbo Informacijskega središča TNP pripravijo sejem biološke prehrane in množično zabavo z živo narodnozabavno glasbo, srečelovom in otroškimi igrami. ${ }^{8}$

Indikativni so tudi prostorski, ne samo časovni premiki. Do prve svetovne vojne so pripravili mašo, sejem in zabavi obeh praznikov (mali šmaren in Anino) pri cerkvi Marije Lavretanske (zgrajena 1690), ki je bila v središču vaškega javnega življenja: tam stojita cerkev in župnišče, nekoč pa še fužine in Attemsova graščina (glej Rutar, 1889; Abram, 1907). Tržnica in zabava sta zdaj kilometer ali dva nižje, na travniku pred Informacijskim središčem TNP, ki je dominantna sodobna stavba.

Travnik pred Informacijskim središčem TNP je največja javna ravna površina $\mathrm{v}$ dolini. Triglavski narodni park je na ta dan gostitelj, saj turističnemu društvu pomaga organizirati celoten sklop dogodkov in pokrije del stroškov. A kot rečeno, razmerja med institucijami so dejansko razmerja znotraj majhne skupine ljudi, ki te institucije upravlja kot pravnoformalne vzvode in priložnosti za realizacijo raznovrstnih (skupnostnih) projektov.

Na biotržnici najdemo prodajalce in blago iz drugih krajev Primorske in Gorenjske. Domačini pravzaprav nimajo kaj prodajati, ker pridelujejo le zase na vrtičkih, živine pa tudi skorajda nimajo več. Nekateri domačini ne morejo prodajati zato, ker nimajo registrirane (obrtne, vrtnarske, predelovalne) dejavnosti. Lokalno proizvodnjo so leta 2013 zastopale dekleta in matere iz Aktiva kmečkih žena, ki so prodajale potico, drobno pecivo in volnene izdelke. Oboje izdelujejo izjemoma. Blago, ki ga ponujajo na tržnici, je tako le deloma namenjeno domačinom, saj lahko sir, jogurt, smetano, zelenjavo, volnene izdelke, pivo, testenine, marmelade in različne zelenjavne namaze ter sprej proti klopom in komarjem - vse to ponujajo stojnice - kupijo v redni prodaji, kjer blago sicer nima oznake »bio«. Biotržnica ima po moje za domačine predvsem simbolni pomen, ker oživlja komunalistično ali kolektivistično moč in funkcijo tradicionalnega cerkvenega in tržnega praznika/rituala nekdanjega Trentarskega senjema, ne more pa oživiti njegovega izvornega objekta menjave (ovac, koz, krav). Za domačine je vsekakor bolj zanimiv popoldanski zabavni del, ko se lahko srečajo in zabavajo z drugimi prebivalci, četudi imajo takrat doma največ dela s turisti. Tako

8 Sklop prireditev se zdaj zaključi v začetku septembra s svečanim koncertom udeležencev mednarodne glasbene šole (Trentarski forum). 
tržnica kot zabava v mesecu juliju pa sta nedvomno privlačni za turiste, pohodnike in druge obiskovalce tega nenavadno množičnega in glasnega dogodka med gorami, prek katerega lahko spoznavajo še lokalno kulturo, ne samo narave.

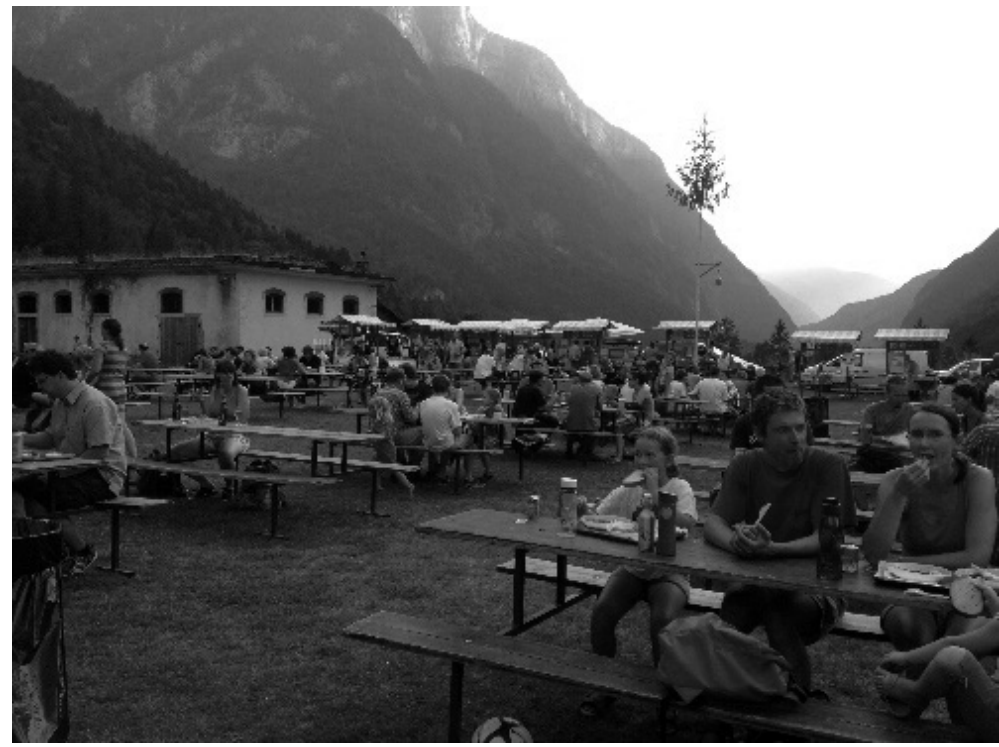

Slika 2: Trentarski senjem 2013, Trenta, 27. julij 2013. Foto: P. Simonič.

Večji del organizacije sejemskega dela Trentarskega senjema sta že leta 1996 prevzela zakonca Marko in Stanka Pretner z že omenjene velike kmetije v Trenti. ${ }^{9} \mathrm{Z}$ dogodkom iz različnih razlogov nista nikoli povsem zadovoljna, a menita, da kot vaška skupnost in družina več ne zmorejo; že to zahteva velike in dodatne napore - ob vseh drugih gospodinjskih in gospodarskih obveznostih. Vedno bolj sodelujejo otroci in drugi člani turističnega društva, ki pomagajo pripraviti klopi in stojnice, na zabavi pa skrbijo za glavni pult s hrano (čevapčiči, svinjski kotleti) in pijačo (pivo, vino).

Pri maši naslednje jutro je manj ljudi kot na zabavi, med prisotnimi pa so številne upokojenke in upokojenci, rezidenčni turisti, pa tudi radovedneži, ki se pripeljejo mimo po prometni cesti proti Vršiču. Podajam odlomek iz terenskih zapiskov, ki najbolje ilustrira dogajanje pri maši dan po tem (Simonič, 2011-2014):

Naslednji dan sva z Markom preostalo pecivo odpeljala pred cerkev v zgornji Trenti ... Pred cerkvijo sva pripravila tri mize s klopmi, vse pecivo zložila na eno od njih in ga pokrila $\mathrm{z}$ belim prtom, »da ga ne bi odnesle mačke«. K maši je prišlo kakih petdeset domačinov ter še pol toliko njihovih sorodnikov in turistov. Osrednji del nagovora je pripadel župniku Ipavcu (»iz znane

9 Marko je redno zaposlen kot vodja Informacijskega središča Triglavskega narodnega parka v Trenti. 
primorske družine«), ki sicer vodi center umirajočih (hospic) na Dunaju. $\mathrm{V}$ skladu z Aninim praznikom je največ pozornosti namenil materinski in družinski ljubezni (sv. Ana je bila Jezusova babica), veliko pa je govoril še o skrbi za bolne in umirajoče.

Po maši ljudje niso bili tako zadržani in tiho, kot je o istem dogodku pred več kot sto leti poročal Rutar (1889). ${ }^{10}$ Ljudje so se veselili družbe, izmenjavali šale in zgodbe, pili vino in pojedli skoraj vse pripravljeno. Ob 13.30 so se razšli, midva z Markom pa sva klopi, ozvočenje in pladnje zložila nazaj v kombi. Klopi sva odpeljala v staro vojašnico (hotel) v Trenti, pladnje in ozvočenje pa v Informacijsko središče TNP. Na koncu sva spredaj na travniku, kjer sta bili biotržnica in zabava, pobrala še dva senčnika in ju odpeljala h gostilni Metoja v vasi Trenta, potem pa sva domov proti vasi Soča odpeljala še novo zaposleno čistilko $\mathrm{v}$ središču TNP. Vse prevoze sva opravila $\mathrm{z}$ njegovim osebnim kombijem. Na koncu si je oddahnil: »Tako, volunterstva je konec ... Vesel sem, da je tole za mano."

Ko sva popoldne čakala na avtobus, ki me bo odpeljal na Vršič, je povedal, da vse travnike tu naokrog kosi v glavnem on, da ljudje nimajo več živine, zato jih to ne zanima. Pošalil se je, da bi lahko dobil nagrado za ohranjanje kulturne krajine.

\section{Zaključek}

Zakon o gozdovih (1953) in Zakon o ustanovitvi TNP (1981) moramo obvezno obravnavati skupaj. S prvim je država onemogočila staro, z drugim pa institucionalizirala novo razvojno strategijo. Obe zakonski intervenciji označujeta prehod od agro-kulturne $\mathrm{k}$ turistično-kulturni in naravovarstveni rabi prostora. Pozabiti pa ne smemo še na druge strese, ki so bili v Posočju pogosti: govorim o ne tako davnih potresih, obenem pa o pogosti grožnji lakote, o življenjsko nevarnem delu $\mathrm{v}$ planinah in gozdovih ipd., o čemer je poročal Rutar (1889). V takih stresnih pogojih bivanja so ljudje zelo dovzetni za novosti in prilagajanje.

Četudi je Trenta vaško okolje, je nesmiselno govoriti o »mehanski solidarnosti« (Durkheim, 1984 [1893]), delujoči po inertnih načelih, in priklenjenosti posameznika. $\mathrm{Ne}$ gre za iracionalnost navad in tradicij, ampak za zavestno manipuliranje domačinov najrazličnejših poklicev $\mathrm{z}$ najrazličnejšimi viri - materialnimi in simbolnimi. Občutek skupnosti je tako posledica trenutnih ekološko-demografskih

10 »Pod lipo pred cerkvijo je stalo nekaj miz s hrano za otroke, naprej mize s steklenicami žganja (pod njimi so hranili kruh v velikih košarah). Po maši se je vse prineslo $\mathrm{k}$ tem mizam in v eni uri je bilo vse razprodano. Potem so šli stran od miz, ločeno po družinah, in nastala je tišina kot pri maši, kot je tukaj zmeraj« (Rutar, 1889, 1580). 
danosti, vendar je hkrati rezultat turizma - širših družbenih omrežij, deloma pa tudi oživljenih arhaičnih institucij, kot je agrarna skupnost (Zakon o ponovni vzpostavitvi lokalnih skupnosti ..., 1994).

Videli smo, da je v dolini Trente kolektivni interes vpisan v vseh sferah življenja: v lastninski strukturi (transhumanca, agrarne skupnosti), organizacijskem sodelovanju in solidarnosti (medsosedska pomoč, zadruge, turistično društvo, aktiv kmečkih žena) ter ritualih (Jožefovo v Trenti, Anino v Trenti, Trentarski senjem, dramska skupina, pevski zbor, tudi lovci in kegljači). Po drugi strani smo videli, da je število prebivalcev zadnjih štirideset ali petdeset let premajhno, da bi obvladovalo večje število institucij, med njimi tudi skupno pašo - prav tisti ekonomski model torej, ki ga je kot dolgoročno nevzdržnega navajal Hardin (1968). Videli smo, da je bilo od 19. stoletja članstvo v agrarni skupnosti jamstvo za obstoj gospodinjstev v dolini, številni pa so morali delati kot gozdni delavci ali se kako drugače preživljati znotraj te strukture lokalnih pravic. Zato lahko v našem primeru pritrdimo Hardinovi tezi, da je skupnostno upravljanje vezano na specifično demografsko podobo lokacije. ${ }^{11} \mathrm{~V}$ Trenti je kontinuiteta neposrednega/participatornega/skupnostnega upravljanja jasno izražena, ima pa različne zgodovinske oblike ter je vedno povezana tudi z ekonomskimi in političnimi pogoji prebivalstva.

V 20. stoletju so se v dolini Trente pojavljale nove institucije, ki so prevzemale skupnostno ali orkestracijsko vlogo agrarne skupnosti, $v$ prvi vrsti mislim na turistično društvo, kulturno društvo in zadrugo. Omejeno število institucij je pod nadzorom majhne skupine ljudi, ki predstavlja okrog 10 odstotkov lokalnega prebivalstva. Zato pri sledenju institucijam (skupnostim) ne smemo spregledati hierarhije družbenih odnosov, ki nujno sledi tem odstotkom. Znanje in moč tudi znotraj majhnih (lokalnih) skupnosti nista enakomerno porazdeljena, kar ima politične in kulturne posledice. To, kar se navzven kaže kot kultura območja, je rezultat miselnega sveta, moči in zmožnosti majhne skupine ljudi, ki vodi te »družbene podsisteme«. Ta skupina materialno, pravno in praznično dediščino prostora prilagaja svojim trenutnim potrebam - precej podobno kot na ravni države in nacije.

Ne moremo torej govoriti o egalitarnosti trentarske družbe in kulture, ker zaradi civilizacijskega izročila taka pač ne more biti, ampak govorimo predvsem o skupnostih

11 Hardinova podmena je, da v populacijsko večjih urbanih središčih in državah skupnostno upravljanje ni možno. Naj le opozorim, da gredo sodobne smeri t. i. aktivnega državljanstva v Veliki Britaniji in Združenih državah Amerike prav v to mikrolokacijsko in mikroskupnostno smer, torej v smer neposrednosti, ki predpostavlja majhno število članov (interesne) skupnosti (McCowan, 2009; Biesta, 2011). Vzgoja za aktivno državljanstvo se je v omenjenih državah pojavila v devetdesetih letih 20. stoletja, njen okvir pa naj bi bilo prostovoljstvo mladih in drugih v neposredni skupnosti (Bezjak, Klemenčič, 2014). To gibanje za (nepolitično-ekonomsko) participacijo sta podpirali tudi vladi v Londonu in Washingtonu, obenem pa spodbujali davčno deregulacijo, privatizacijo, korporacijske koncesije in javno zadolževanje. 
in kolektivnostih na ravni daljšega ali krajšega medsebojnega sodelovanja (Kropotkin, 1972 [1902]): medsosedska pomoč, zadruga, agrarna skupnost, Trentarski senjem idr. Poleg tega delujejo solidarnostni/redistributivni/podporni družbeni mehanizmi (prim. Tönnies, 2001 [1887]; Polanyi 1944; Sahlins 1972) v družinah ali skozi prenos dobička agrarne skupnosti na krajevno skupnost; tudi v pravici dostopa do cenejšega lesa za nečlane agrarnih skupnosti, $v$ ciljih zadruge, $v$ pomoči pri reševanju stanovanjskega problema mladih ipd. Nobenega dvoma ni, da so lokalne kolektivnosti (institucije, združbe, solidarnosti) v dolini Trente vedno igrale pomembno vlogo. ${ }^{12}$

Znotraj trentarske družbe ni veliko sledi o notranjih tržnih razmerjih med člani, temveč lahko v skladu s Sahlinsovo (1972) klasifikacijo najdemo predvsem generalizirano recipročnost znotraj družin in uravnoteženo recipročnost znotraj drugih opisanih institucij. Negativna (tržna) recipročnost je obrnjena navzven, proti tujcem (turistom, planincem, gozdnemu gospodarstvu ipd.).

\section{Viri in literatura}

Abram, J., Opis Trente. Planinski vestnik (Feljton) 13/1-12, Ljubljana 1907.

Barnard, A., Mutual aid and the foraging mode of thought: Reading Kropotkin in the Kalahari, v: Diverse people unite: Two Lectures on Khoisan Imagery and the State (Occasional Papers 94), Edinburgh 2003, str. 49-87.

Barth, F., Ecologic Relationships of Ethnic Groups in Swat, North Pakistan, American Anthropologist 58, 1956, str. 1079-1089.

Baudrillard, J., For a Critique of the Political Economy of the Sign, St. Louis 1981.

Baudrillard, J., Simulaker and simulation. The perfect crime, Ljubljana 1999.

Bezjak, S., Klemenčič, E., Learning Active Citizenship through Volunteering in Compulsory Basic Education in Slovenia, Traditiones 43 (32), 2014, str. 51-65.

Biesta, G., Learning Democracy in School and Society: Education, Lifelong Learning, and the Politics of Citizenship, Rotterdam 2011.

Celec, B., Nad Janšo zaradi Trente, Slovenske novice, 20. marec 2014.

Cohen, A. P., The symbolic construction of community, London, New York 1998.

Douglas, M., How Institutions Think, New York 1986.

Durkheim, E., The Division of Labour in Society, London 1984.

Feeny, D., Berkes, F., McCay, B. J., Acheson, J. M., The Tragedy of the Commons: Twenty-Two Years Later, Human Ecology 18 (1), 1990, str. 1-19.

12 V besedilu se nisem želel podrobneje ukvarjati s sicer pomembno institucijo - Rimskokatoliško cerkvijo, opozoril sem zgolj na središčno pozicijo, ki jo je Cerkev zasedala v vaških skupnostih Soče in Trente. 
Gluckman, M., The Kingdom of the Zulu of South Africa, v: African Political Systems (ur. Fortes, M., Evans-Pritchard, E. E.), London, New York, Toronto 1940.

Gosar, A., Socialna ekonomija, Ljubljana 1924.

Graeber, D., Fragments of Anarchist Anthropology, Chicago 2004.

Gupta, A., Ferguson, J., Beyond Culture: Space, Identity, and the Politics of Difference, Cultural Anthropology 7 (1), 1992, str. 6-23.

Hardin, G., The Tragedy of Commons, Science 62 (2859), 1968, str. 1243-1248.

Hardt, M., Negri, A., Empire, Cambridge, London 2001.

Harvey, D., A brief history of neoliberalism, New York 2005.

Ingold, T., Globes and Spheres: The Topology of Environmentalism, v: Environmentalism: The View from Anthropology (ur. Milton, K.), London 1993, str. 31-42.

Kardelj, E., Smeri razvoja političnega sistema socialističnega samoupravljanja, v: Sodobnost 27 (3), 1979, str. 265-274.

Knežević Hočevar, D., Antropološka demografija: spodletela združitev antropologije in demografije?, Glasnik Slovenskega etnološkega društva 48 (1-2), 2008, str. 5-12.

Komac, V. T., Zakladnica bovške preteklosti, Idrija 2003.

Kozorog, M., Na zadnji poti z Dantejem Alighierijem po Tolminu, Glasnik Slovenskega etnološkega društva 46 (3-4), 2006, str. 75-84.

Kozorog, M., Antropologija turistične destinacije $v$ nastajanju: Prostor, festivali in lokalna identiteta na Tolminskem, Ljubljana 2009.

Kropotkin, P., Mutual Aid; A Factor of Evolution, New York 1972.

Ledinek Lozej, Š., Paša in predelava mleka v planinah Triglavskega narodnega parka, Traditiones 42 (2), 2013, str. 49-68.

Low, Setha M., Lawrence-Zúñiga, D. (ur.), The Anthropology of Space and Place: Locating Culture, Malden 2003.

Marušič, B., Domoznanska literatura o Bovcu in o Bovškem, v: Soški razgovori 1 (ur. Kunaver, J.), Bovec 2002, str. 131-136.

McCowan, T., Rethinking Citizenship Education: A Curriculum for Participatory Democracy, London, New York 2009.

Mencej, M., Podjed, D. (ur.), Ustvarjanje prostorov, Ljubljana 2010.

Miklavčič Brezigar, I., Prispevek k etnološki podobi Bovškega, v: Pokrajina in ljudje na Bovškem (ur. Kunaver, J.), Ljubljana 1988, str. 81-108.

Netting, R., Smallholders, Householders: Farm Families and Ecology of Intensive, Sustainable Agriculture, Stanford 1993. 
Ostrom, E., Beyond Markets and States: Polycentric Governance of Complex Economic Systems, Bloomington 2009.

Palsson, G., Human-environmental relations: orientalism, paternalism, communalism, v: Nature and Society (ur. Descola, P., Palsson, G.), London, New York 1996, str. 63-81.

Peterlin, S., Nastanek in razvoj TNP, v: Triglavski narodni park - Vodnik (ur. Fabjan, I. in drugi), Bled 1985, str. 6-9.

Picketty, T., Capital in the Twenty-First Century, Cambridge, London 2014.

Poljak Istenić, S., Tradicija sodobnosti: Janče - zeleni prag Ljubljane, Ljubljana 2013.

Proudhon, P. J., System of Economical Contradictions or, The Philosophy of Misery, Cambridge 2008.

Rapport, N., Overing, J., Social and Cultural Anthropology: The Key Concepts, London 2000.

Rutar, S., Das Annenfest in der Trenta, Leibacher Zeitung, 14. avgust 1889.

Sahlins, M., Stone Age Economics, New York 1972.

Simonič, P., Habitat in habitus: Antropološki izzivi upravljanja varovanih območij narave, v: Uporaba prostorov (ur. Klaus, S., Kvartič, A.), Ljubljana 2011, str. 47-55.

Simonič, P., Terenski zapiski in fotografije iz raziskovalnega projekta Triglavski narodni park: dediščina, akterji, strategije, vprašanja, rešitve, Ljubljana 2011-2014.

Simonič, P., Naravne, gospodarske, politične in demografske danosti Trente $\mathrm{v}$ Triglavskem narodnem parku, Traditiones 42 (2), 2013, str. 69-84.

Simonič, P. (ur.), Integralno gradivo s terenskih vaj $v$ Trenti: Prazniki in skupnosti (Študentski zapiski pri predmetu Aplikativna antropologija in kulturni menedžment, 30. 11.-1. 12. 2012), Ljubljana 2014a.

Simonič, P. (ur.), Tematsko urejeni izpiski iz intervjujev na temo Skupnosti in prazniki v Trenti (december 2012), Ljubljana 2014b.

Southall, A. W., The City in Time and Space, Cambridge 1998.

Statistični urad Republike Slovenije, Popis prebivalstva, gospodinjstev in stanovanj, Ljubljana 2002.

Steward, J. H., Theory of Culture Change: The Methodology of Multilinear Evolution, Urbana 1955.

Stiglitz, J. E., The Price of Inequality. How Today's Divided Society Endangers Our Future, New York, London 2011.

Šaver, B., Nazaj v planinski raj: Alpska kultura slovenstva in mitologija Triglava, Ljubljana 2005. 
Šuštar, M. (ur.), Zadružništvo včeraj, danes, jutri: Zbornik posvetovanja ob 130-letnici rojstva Frana Jakliča, ustanovitelja prve rajfajznovke na Kranjskem, Dobrepolje, Ljubljana 1999.

Tönnies, F., Community and Civil Society, Cambridge 2001.

Turistično društvo Soča Trenta, Trenta: Štirje letni počasi, http://www.soca-trenta.si [5. 4. 2014].

Turner, V., Forest of Symbols: Aspects of Ndembu Ritual, Ithaca 1967.

Vayda, A. P., Rappaport, Roy A., Ecology, Cultural and Noncultural, v: Introduction to Cultural Anthropology: Essays in the Scope and Methods of the Science of Man (ur. Clifton, J. A.), Boston 1968, str. 477-497.

Vranješ, M., Zelena puščava: Kulturna krajina iz 'domačinskega zornega' kota, v: Etnolog 15, 2005, str. 281-301.

Vranješ, M., Cultural landscape and Triglav national park from the 'native point of view': The case of Trenta valley, Slovenia, v: Ethnography of protected areas: Endangered habitats, endangered cultures (ur. Simonič, P.), Ljubljana 2006, str. 71-84.

Vranješ, M., Prostor, teritorij, kraj: Produkcije lokalnosti v Trenti in na Soči, Koper 2008. 
Peter Simonič

\section{Pretekle in sodobne oblike skupnega v dolini Trenti}

Ključne besede: Alpe, gospodinjstva, gmajne, skupnosti, zadruge, rituali, menedžment, demografija, okolje

Sodobna družboslovna in humanistična razmišljanja ter medijski diskurzi se pri iskanju rešitev za težave $\mathrm{v}$ centraliziranem, tehnologiziranem, kapitaliziranem in politično zastopniškem svetu pogosto zgledujejo po predindustrijskih ali etnografskih organizacijskih modelih, ki so jih zabeležili etnologi in antropologi. Pri tem prihaja do idealiziranja in posploševanja, saj se zanemarja številne konkretne okoliščine, ki so te modele omogočile ali jih še omogočajo.

Razloge za oblikovanje kolektivnih institucij na izbrani mikrolokaciji avtor išče predvsem v okoljskih in demografskih danostih, ki so v slovenskih antropoloških spisih pogosto spregledane. K temu dodaja ekonomske, politične in kulturne dejavnike, čeprav jih ne postavlja v hierarhični odnos.

Avtor išče znamenja skupnostnih prizadevanj v Trenti na ravni gospodinjstev, soseščin, vasi, agrarnih skupnosti, zadrug, kulturnih in turističnih društev ter praznikov. Ugotavlja, da je v majhni skupnosti recipročnost generalizirana ali uravnotežena, zelo redko pa je negativna $\mathrm{v}$ smislu tržnih menjav med njenimi člani, $s$ čimer pritrjuje Sahlinsovi konceptualizaciji razmerij med družbenimi odnosi in materialnimi tokovi.

Posebna pozornost je posvečena tržno-religioznemu lokalnemu prazniku Trentarski senjem. Z njegovo analizo je mogoče zelo plastično prikazati, kako na simbolni (prostorsko-časovni) ravni odsevajo spremembe $\mathrm{v}$ družbeno-ekonomski strukturi doline v 20. stoletju. 
Peter Simonič

\section{Past and Present Forms of the Communal in the Trenta Valley}

Keywords: Alps, households, commons, communities, cooperatives, rituals, management, demography, environment

Contemporary social sciences, humanities and mass media discourses are increasingly searching for a solution to the problems of the centralised, capitalised, technologically-conditioned and politically-represented world. In this search they are often inspired by pre-industrial organizational models which have been recorded by ethnologists and anthropologists. Since they often neglect the concrete circumstances which enabled these models, modern suggestions run the risks idealization and generalization. This paper, thus, examines the creation of institutions in the micro-location of Trenta, while considering environmental and demographic factors (which are frequently overlooked in Slovenian anthropological research and writings). Economic, political and cultural factors are also considered, although not in a hierarchical relationship to environment and demography. The paper seeks out signs of collective efforts at the level of households, neighbourhoods, villages, agrarian communities (commons), cooperatives, and local tourism. Special attention is paid to Trentarski senjem, a market and religious holiday. Its analysis enables very plastic presentation of the symbolic (spatial-temporal) shifts taking place in the socioeconomic structure of the Trenta Valley in the $20^{\text {th }}$ century. 